\title{
ARTIGOS
}

Recebido em 25.10.2012. Aprovado em 26.07.2013

Avaliado pelo sistema double blind review. Editor Científico: André Lucirton Costa

DOI: http://dx.doi.org/10.1590/So034-759020140305

\section{INTERNET E PARTICIPAÇÃO: O CASO DO ORÇAMENTO PARTICIPATIVO DIGITAL DE BELO HORIZONTE}

\author{
Internet and participation: the case of digital participatory budgeting in \\ Belo Horizonte \\ Internet y participación: el caso del presupuesto participativo digital de \\ Belo Horizonte
}

\begin{abstract}
RESUMO
Este artigo investiga as representações sociais que emergem da participação pública mediada pelo uso de Tecnologias de Informação e Comunicação (TIC). A prefeitura de Belo Horizonte, em 2006, usou pela primeira vez a TIC no Orçamento Participativo Digital (OP Digital). Foi uma escolha da população das obras prioritárias para o biênio seguinte. O OP Digital foi repetido em 2008 e 2011, mas com participação inferior à obtida na primeira edição. Realizamos este trabalho para compreender o uso da internet pelo cidadão na tomada de decisão pública e para explicar a diminuição da sua participação. Os procedimentos metodológicos estão ancorados na teoria das representações sociais e na análise crítica do discurso de 101 textos - da imprensa e de órgãos públicos ou representantes do governo. Os resultados nos indicam que não está sendo explorado o potencial de interação e construção coletiva da internet, ancorando a nova prática em uma votação, dessa forma, trivializando-a. Essa pode ser uma das razões para o abandono da participação. PALAVRAS-CHAVE | Orçamento Participativo Digital, Tecnologia de Informação e Comunicação, Teoria das Representações Sociais, análise crítica do discurso, e-participação.
\end{abstract}

\begin{abstract}
This research aims at investigating the social representations in public participation decision-making using ICT (Information and Communication Technologies). The Belo Horizonte City Hall used ICT for the first time in 2006, in the Digital Participatory Budget (OP Digital). It was a choice made by the population of the implementation of public works for the next two years. The OP Digital was applied again in 2008 and 2011, but with a lower participation than its first edition. We performed this study to understand the use of Internet by citizens in public decision making and to explain the decline of popular participation. The methodological approach is based in social representations theory and in the critical discourse analysis of 101 texts - from the press and from public agencies or government representatives. Our results suggest that current political strategies were not fully exploiting the potential for interaction and collective construction offered by the Internet, trivializing it. This may be one of the reasons of lower participation.
\end{abstract}

KEYWORDS I Digital Participatory Budget, ICT, Social Representations Theory, Critical Discourse Analysis, e-Participation.

\section{RESUMEN}

Este artículo investiga las representaciones sociales de la participación pública con el uso de Tecnologías de la Información y Comunicación (TIC). La prefectura de Belo Horizonte, en 2006, usó por primera vez la TIC en el Presupuesto Participativo Digital. Fue una elección de la población de las obras prioritarias para el bienio siguiente. El PP-Digital fue repetido en 2008 y 2011, pero con participación inferior a la obtenida en la primera edición. Realizamos este trabajo para comprender el uso de internet por el ciudadano en la toma de decisión pública y para explicar la disminución de su participación. Los procedimientos metodológicos están anclados en la Teoría de las Representaciones Sociales y en el análisis crítico del discurso de 101 textos - de la prensa y de órganos públicos o representantes del gobierno. Los resultados nos indican que no está siendo explotado el potencial de interacción y construcción colectiva de internet, anclando la nueva práctica en una votación, de esa forma se trivializa la misma. Esta puede ser una de las razones para el abandono de la participación.

PALABRAS CLAVE I Presupuesto Participativo Digital, Tecnología de la Información y Comunicación, Teoría de las Representaciones Sociales, análisis crítico del discurso, e-participación. 


\section{INTRODUÇÃO}

O uso e as implicações sociais das Tecnologias de Informação e Comunicação (TIC) têm conquistado espaço nos fóruns acadêmicos, configurando uma área de produção científica no campo de sistemas de informação (SI). A observação desse fenômeno nos países em desenvolvimento é particularmente interessante, pois expande as fronteiras do campo, propondo novos temas ou chamando a atenção para dimensões da inovação em SI que têm recebido pouca atenção do mainstream da pesquisa (Avgerou, 2008). Um conjunto de questões emerge desse contexto, desde diferentes abordagens de projeto de SI até que intervenções sócio-organizacionais seriam mais apropriadas. Há estudos que focalizam a profundidade e os efeitos de longo prazo que as TIC podem provocar nas instituições sociais dos países em desenvolvimento, enquanto outros se debruçam sobre como as práticas mediadas por tecnologia são estruturadas para suportar a melhoria dos serviços sociais e da governança (Avgerou, 2008). Há um interesse crescente, tanto na pesquisa acadêmica como na prática governamental, em novas formas de relacionamento entre Estado e cidadãos, especialmente na participação pública.

O orçamento participativo (OP) é um exemplo de participação pública, já que permite aos cidadãos influenciar ou decidir sobre os orçamentos públicos, geralmente o orçamento de investimentos de prefeituras municipais. Apesar de diferentes metodologias e versões de OP terem sido construídas, costumam contar com assembleias abertas e periódicas e etapas de negociação direta com o governo. A experiência de Porto Alegre tem inspirado governos de diversas cidades no mundo a estabelecerem seu processo de elaboração de orçamento e de planejamento com a participação dos cidadãos.

Em 1993, Belo Horizonte (BH) implementou sua versão de OP e, em 2006, lançou um OP "digital”, numa tentativa de usar a internet para aproximar os cidadãos que não estavam participando do OP na sua forma presencial. O OP Digital foi apresentado como uma "modalidade" alternativa, permitindo a "votação" on-line de obras públicas a serem desenvolvidas nos anos posteriores. A experiência digital foi repetida em 2008 e 2011. Surpreendentemente, a participação pública de BH diminuiu ao longo do tempo: aproximadamente 173 mil votantes na primeira edição (2006), 124 mil na segunda (2008) e, na terceira, 25 mil (2011). Quisemos, assim, investigar a participação na tomada de decisão do orçamento público mediada por TIC e entender que razões puderam contribuir para a redução na participação. Com esse objetivo, escolhemos como quadro teórico a teoria das representações sociais (TRS). Serge Moscovici (2001) defende que, por meio das representações sociais, os objetos passam a fazer sentido no mundo das pessoas e, assim, elas podem interagir e comunicar-se com os outros atores sociais. Buscamos compreender a representação social do OP Digital de BH. Em termos de abordagem metodológica, adotamos análise crítica do discurso (CDA). Essa combinação de TRS como lente teórica e CDA como desenho metodológico é original e representa uma contribuição de nossa pesquisa. Na prática, a nossa contribuição é direcionada aos gestores que se deparam com desafios ao lidar com a participação do público por meio das TIC.

Este artigo está estruturado da seguinte forma: primeiro, recapitulamos conceitos relacionados à sociedade da informação, internet, democracia e participação pública. Depois, apresentamos a TRS, a CDA, e descrevemos o caso do OP Digital da cidade de BH. Seguimos com a análise dos dados e a discussão dos resultados, invocando as vozes da imprensa e do governo para entender os processos de inclusão e de participação na tomada de decisão pública. Na conclusão, apresentamos os principais resultados e uma reflexão sobre as implicações de nossas escolhas teórico-metodológicas para um melhor entendimento deste caso particular de TIC e participação pública.

\section{INTERNET E E-PARTICIPAÇÃO}

Por décadas, acadêmicos, políticos e ativistas vêm anunciando as implicações do uso das TIC em geral, e, especialmente, da internet, e o seu potencial para revolucionar vários aspectos da sociedade, incluindo negócios, educação, governo e democracia. Termos como e-negócios, e-educação, e-governo e e-democracia surgiram, tentando reforçar os aspectos particulares dessas novas formas de práticas sociais.

No campo das implicações políticas das TIC, e particularmente da internet, diferentes autores têm opiniões que variam amplamente. De um lado, temos os entusiastas, que veem o potencial da tecnologia para a construção de um "mundo melhor", tais como Negroponte (1995) e Dertouzos (1997). Esses autores, em geral, propõe o uso das TIC como um caminho para a democracia, a equidade e a participação (e também conhecimento e plenitude de vida). Para os otimistas, a internet: tem o potencial de estender a esfera pública e atuar como uma força democrática, ampliando a confiança e a participação; é capaz de criar um espaço público sem limites; e está trazendo oportunidades para a provisão de informação, a comunicação interativa e o engajamento cívico (Ainsworth, Hardy \& Harley, 2005).

Há, porém, pontos de vista antagônicos à visão otimista, e outros autores descrevem-na como utópica (Kling, 1996) ou romântica (Winner, 1986). Afirmam que o desenvolvimento 
da era da informação sugere um aumento da distância entre os que detêm o poder e aqueles que a ele não têm acesso, mais riqueza para os ricos e maior controle para os mais preparados para exercê-lo (tais como os governos e as grandes empresas). Essa posição, chamada pessimista ou antiutópica (Kling, 1996), aponta as discrepâncias no acesso à internet relacionadas a área geográfica, raça, gênero e classes, e seu uso para propósitos autoritários (Ainsworth et al, 2005). Ainda nesse grupo de autores, há os que apontam que, especialmente para os países emergentes, o discurso do uso das TIC para o desenvolvimento, feito pelas agências internacionais, tais como o Banco Mundial, replicam e expandem, dentro do discurso desenvolvimentista, uma visão de mundo que é norte-americana (Thompson, 2004).

Para além dessas duas visões antagônicas, em estudos mais recentes, foram identificados autores numa terceira posição: a utilitária (Ainsworth et al, 2005). Esse posicionamento otimista, mas não utópico - parece ser também a posição de alguns textos brasileiros (Pinho, 2011; Savazoni \& Cohn, 2009), que reconhecem na internet algum potencial para uma forma de democracia mais participativa. Na literatura, há quatro temas principais ao se falar de agenda de participação: quem define a agenda de participação; que habilidades os stakeholders devem ter para participar e como elas podem ser fortalecidas; qual o papel das condições institucionais para a participação efetiva; e como as experiências participatórias locais se integram em redes mais amplas para tornarem-se sustentáveis (Puri \& Sahay, 2007).

Participação eletrônica, ou simplesmente e-participação, por vezes, é tratada como um subcampo da democracia eletrônica (Macintosh, 2004). Susha and Grönlund (2012) descrevem, no entanto, duas fontes de discrepância entre esses dois conceitos. Primeiro, há uma falta de lógica interna em vincular e-participação com regimes democráticos baseando-se exclusivamente na governança. Em segundo lugar, há uma discrepância no que diz respeito ao âmbito de aplicação e métodos usados nos dois campos. Embora a pesquisa sobre o tema apareça como um domínio bastante instrumental, em grande parte orientada para a utilização de ferramentas TIC, o seu alcance é muito mais amplo e engloba a participação dos cidadãos em praticamente qualquer serviço público, e não necessariamente na política ou na governança relacionada ao campo (Susha \& Grönlund, 2012). A e-participação está relacionada a oportunidades para consulta e diálogo entre o governo e cidadãos utilizando uma série de ferramentas de TIC, incluindo e-votação - o uso de TIC para apoiar o processo democrático do voto (Macintosh, 2004). E-participação, entretanto, é muito mais do que votar (Rose, Grönlund \& Andersen, 2007); inclui a extensão e a transformação da participação em processos democráticos e consultivos mediados pelas TIC (Sæbø, Rose \& Flak, 2008).

Ainda assim, há barreiras e desafios a enfrentar, tais como complexidade social, dependência tecnológica e compreensão sobre e-participação (Macintosh, 2007). Muitos cidadãos demonstram falta de interesse em participar das decisões governamentais e sentem-se insatisfeitos com a política, fator que poderia ser alterado se os cidadãos entendessem o potencial que a e-participação tem de se transformar em uma ponte sobre a separação que existe entre eles e o governo (Boon, Jansen \& Veenestra, 2011).

Ainda existem lacunas a serem preenchidas no que diz respeito a novas estratégicas de inclusão do cidadão em decisões públicas. A experiência de BH combina dois fenômenos que têm sido estudados separadamente: de um lado, as várias modalidades de OP; de outro, o uso de internet para aproximar os cidadãos dos seus governos. Nosso trabalho visa avançar a compreensão dessa nova modalidade de OP, chamada OP Digital, e entender a diminuição da participação popular ao longo dos anos. Para tanto, utilizamos, no estudo, a TRS.

\section{TEORIA DAS REPRESENTAÇÕES SOCIAIS}

As pesquisas em Administração abarcam, muitas vezes, investigações de fenômenos complexos, nos planos individual, organizacional ou social, os quais necessitam de uma abordagem mais completa, característica da ação humana. A TRS é uma opção ao desenvolvimento de estudos focados não apenas em fatos, dados e opiniões formais, mas, sim, num efetivo entendimento de sentimentos, percepções e valores compartilhados pelos sujeitos (Vergara \& Ferreira, 2005).

Serge Moscovici introduziu e popularizou o conceito de representação social no campo da psicologia social, a partir de seus estudos sobre as diversas maneiras pelas quais a psicanálise era difundida e entendida na França (MOSCOVICl, 1961). Esses estudos marcaram o estabelecimento de uma percepção inovadora a respeito da integração entre os fenômenos perceptivos individuais e sociais. Segundo Moscovici (2001), o termo representações sociais refere-se ao conjunto de percepções, conceitos e explicações originados na vida cotidiana, no curso das comunicações interpessoais. Constitui uma das formas de entendimento do mundo concreto, atuando por meio de observações, de análises dessas observações e de noções e linguagens de que os indivíduos se apropriam. Sob a ótica dessa teoria, sempre que um novo fenômeno, evolucionário ou revolucionário, permeia um grupo social, ele passa por um processo de apropriação que nunca é neutro. Ao contrário, ele se configura na construção de imagens, ideias e conotações já presen- 
tes naquela população (Audebrand \& lacobus, 2008). As representações e práticas sociais estão relacionadas umas com as outras e influenciam-se mutuamente ao longo do tempo (Vaast \& Walsham, 2005). A TRS revela-se útil na busca de uma melhor compreensão das práticas coletivas, porque as representações são compartilhadas; elas nos ajudam a dar sentido ao mundo, agir e comunicar-nos uns com os outros (Abric, 1994; Moscovici, 2001).

Uma representação social elabora-se de acordo com dois processos fundamentais: a ancoragem e a objetificação. Mediante o processo de ancoragem, as pessoas convertem o objeto social em um instrumento de que elas podem dispor, e esse objeto é colocado numa escala de preferência nas relações sociais existentes. A objetificação faz com que se torne real um esquema conceptual, possibilitando a materialização de uma imagem (Moscovici, 2001). Ela tem, então, a função de permitir a um grupo compartilhar melhor a realidade em que vivem seus membros. É dessa forma que os conceitos científicos, técnicos e abstratos são transformados em conceitos compreensíveis, familiares e seguros (Vaast, 2007).

A ancoragem envolve duas fases: a categorização e a integração. A categorização dá-se mediante a escolha de um dos protótipos guardados na memória, o qual é comparado ao objeto a ser representado, e se decide se ele pode ser incluído na classe em questão. A integração envolve retirar alguma coisa do anonimato e incluí-la na matriz de identidade da nossa cultura, conferindo um valor funcional do conteúdo representacional, tornando, assim, o objeto disponível para uso (Audebrand \& lacobus, 2008; Moscovici, 2001).

Na objetificação, ocorrem três fases: seleção, esquematização e naturalização. A seleção envolve selecionar e descontextualizar elementos do que se vai representar, operando, assim, um enxugamento do excesso de informação. Na classificação, organizam-se as partes do meio ambiente e, mediante seus cortes, introduz-se uma ordem que se adapta à preexistente, atenuando o choque de toda e qualquer nova concepção. Procedendo assim, aquele objeto que era misterioso foi devidamente destrinchado, recomposto, e agora torna-se algo efetivamente objetivo, palpável, passando a parecer natural. A naturalização é a cristalização do complexo, na qual o símbolo torna-se real e passa a ser incorporado pelos sujeitos (Audebrand \& lacobus, 2008).

A ancoragem está dialeticamente ligada à objetificação, permitindo a incorporação do novo nas redes de categorias que o indivíduo possui (Moscovici, 2001). Cada fase traz novos elementos à representação social do objeto e participa da sua construção, até que a representação alcance uma relativa estabilidade. De fato, o processo pode nunca estar definiti- vamente acabado (Audebrand \& lacobus, 2008). Esse processo dinâmico pode ser mais bem ilustrado pela figura que matematicamente conhecemos pelo símbolo do infinito. A Figura 1 mostra a ondulação em que a ancoragem leva à objetificação e vice-versa.

\section{Figura 1. Apresentação dinâmica do processo representacional}

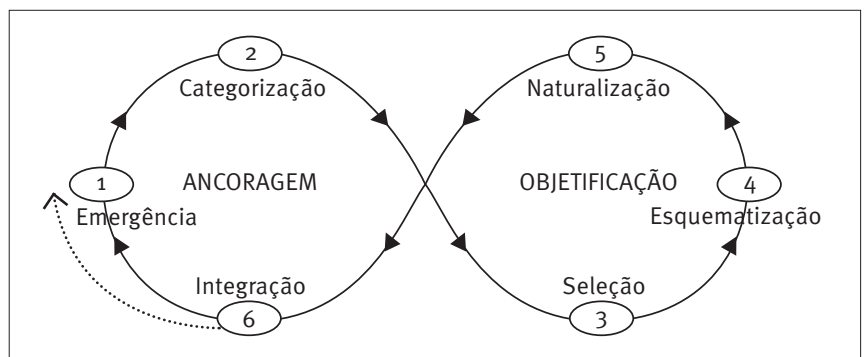

Fonte: Audebrand e Lacobus (2008).

Os processos de ancoragem podem falhar de duas formas: por deficiência ou excesso (Quadro 1). Por excesso, quando a nova prática social apresenta pouco ou nenhum aspecto distintivo de outras práticas sociais. Nesse caso, ocorre a trivialização, que é o ato de tornar o objeto trivial, comum, ordinário, negligenciando a sua originalidade. Por deficiência, quando a nova prática social é apresentada como pouco ou nada em comum com outras práticas sociais, assumindo um caráter de exoticização (Audebrand \& lacobus, 2008). Da mesma forma, a objetificação pode falhar por excesso ou deficiência (Quadro 1). Por excesso, quando a prática social é esvaziada dos seus aspectos simbólicos e emblemáticos, de tal forma que é rendida ao aspecto de uma coisa ordinária, processo chamado de reificação. Ela pode pecar por deficiência quando é apresentada como uma prática social desconectada do mundo tangível e da realidade concreta, permanecendo em tão alto nível de abstração que é inalcançável: a abstratização (Audebrand \& lacobus, 2008).

\section{Quadro 1. Processos de representação e as formas que podem falhar}

\begin{tabular}{l|l|l}
\hline & Deficiência & Excesso \\
\hline Ancoragem & Exoticização & Trivialização \\
\hline Objetificação & Abstratização & Reificação \\
\hline
\end{tabular}

Fonte: Audebrand e Lacobus (2008).

O uso de representações sociais como lente teórica para estudar a implementação de SI, como alternativa à pesquisa sociocognitiva, já foi utilizada previamente (Contarello \& Sarrica, 2007; 
Gal \& Berente, 2008; Pawlowski, Kaganer \& Cater, 2007; Vaast, 2007). Os estudos de Vaast (2007), Kaganer and Vaast (2010) e Gal and Berente (2008) mostram que as representações sociais são uma forma de obter uma visão rica e variada e compreender o conteúdo que faz sentido para os membros de um grupo, bem como a importância dos aspectos sociais que fornecem um pano de fundo para esse contexto. Para Gal and Berente (2008), o uso da abordagem das representações sociais pode produzir explicações mais fundamentais das dificuldades e complexidades encontradas nesse processo. A TRS reconhece o contexto social mais amplo, como as representações sociais evoluem ao longo do tempo e os processos coletivos pelos quais são moldadas, e pode, portanto, oferecer explanações mais ricas na implementação de SI.

\section{ABORDAGEM DE PESQUISA}

O tema principal desta pesquisa é o uso das TIC na participação pública. Para estudá-lo, nós combinamos a TRS como referencial teórico e a CDA como abordagem metodológica. A CDA será descrita na próxima seção. Essa combinação teórico-metodológica é coerente com a natureza ontológica e epistemológica que permeia a visão e as escolhas dos pesquisadores: o interpretativismo crítico (Pozzebon, 2003).

Neste estudo, definimos que ser crítico significa ir além da simples compreensão das interações sociais baseada nas diferentes interpretações das pessoas que adotam e usam as TIC. Ambicionamos considerações mais amplas a respeito de poder e controle social (Doolin, 1998; Pozzebon, 2003). Consideramos que, para adotar uma visão crítico-interpretativa, não precisamos necessariamente nos ancorar na teoria crítica de Habermas e/ou da Escola de Frankfurt, ou mesmo nos trabalhos de Foucault (como proposto por alguns autores, como Brooke (2002)). O que almejamos é um posicionamento crítico e reflexivo na análise de fenômenos complexos no campo de SI.

É preciso, ainda, relatar que nossa posição epistemológica, neste trabalho, é de que a tecnologia é um artefato humano, socialmente construído pelas interações humanas, coalizões e escolhas, que simultaneamente restringem e possibilitam a ação humana (Pozzebon, 2003). Da mesma forma, o conhecimento que produzimos a respeito das tecnologias é uma construção social. Tanto a TRS quanto a CDA representam correntes teóricas e metodológicas que se inserem numa ontologia crítico-interpretativa e refletem uma epistemologia construtivista.

\section{Procedimentos metodológicos}

A nossa abordagem metodológica visa à exploração do discurso como constitutivo dos fenômenos sociais. A CDA tem sido descrita como uma abordagem adequada para produzir insights úteis e relevantes na forma como o discurso reproduz (ou resiste a) desigualdade política e social, abuso de poder e dominação (Ainsworth et al, 2005). Um dos autores da CDA é Fairclough (1995), que explora as imbricações entre linguagem e práticas socioinstitucionais e estruturas políticas e sociais mais amplas. Cukier, Ngwenyama, Bauer and Midletton (2008) enfatizam que a CDA “questiona" textos com o objetivo de expor estruturas profundas, distorções comunicativas sistemáticas e relações de poder subjacentes ao discurso.

Entre os estudos que usam a CDA em SI, Thompson (2004) é particularmente didático expondo o método de análise. Para ele, o trabalho de Fairclough $(1995,1996)$ posiciona as estruturas sociais num relacionamento dialético com as atividades sociais. A parte crítica do método diz respeito ao uso da linguagem e ao exercício do poder, e a parte da análise do discurso destaca os textos como uma das evidências principais de estruturas sociais, relações e processos. A CDA relaciona textos do micronível (o nível do texto) a estruturas de poder macro (prática sociocultural) que tais textos reproduzem. Na CDA, a prática discursiva é o mediador entre os níveis macro e micro (Figura 2).

A fase de interpretação pode envolver uma variedade ampla de conceitos e estratégias, tais como conceitos analíticos, posicionamento, narrativa, metáfora e reestruturação. $\mathrm{Na}$ nossa análise, optamos por identificar, com base nos textos, a produção de representações sociais.

Figura 2. Dimensões do discurso e da análise do discurso

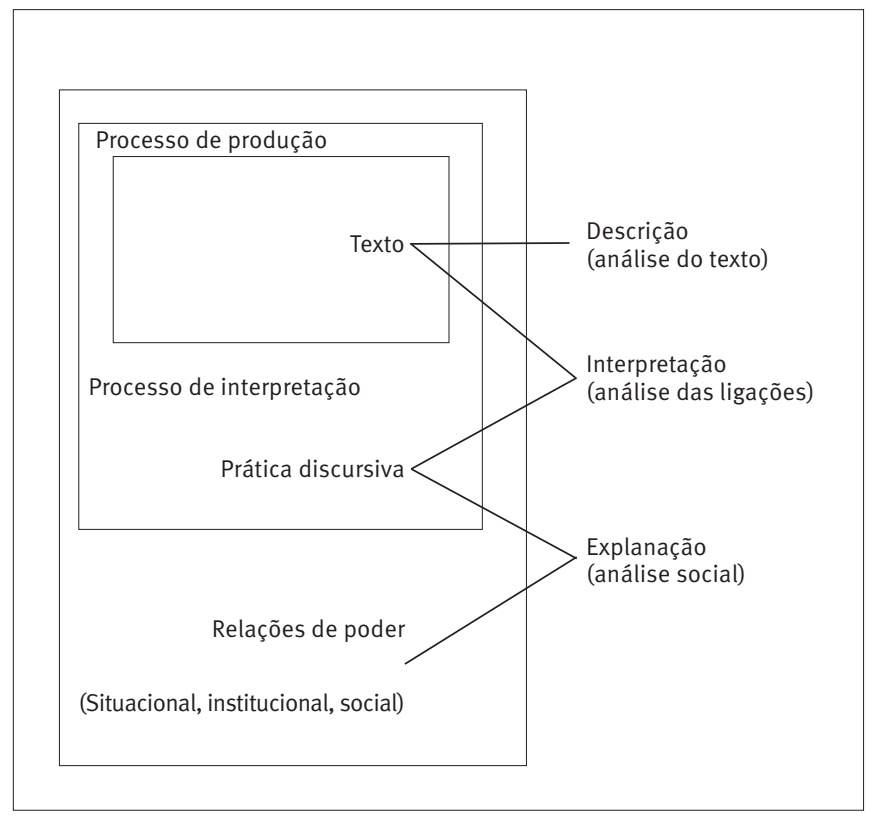

Fonte: Thompson (2004). 


\section{Coleta e análise dos dados}

A operacionalização da CDA ocorreu em três etapas: (1) seleção e organização dos dados, (2) leitura dos textos e interpretação das observações empíricas e (3) explanação dos resultados.

\section{Seleção e organização dos dados}

Usamos múltiplas fontes de material empírico, como sugerido por Ngwenyama and Lee (1997) e Cukier et al. (2008). No total, foram utilizados 101 documentos (todos os que foram localizados): 60 da imprensa e 41 de órgãos públicos ou fontes governamentais, conforme discriminado na Tabela 1.

Depois da seleção, os dados foram organizados. Tendo coletado dois conjuntos discretos de textos - os da imprensa e aqueles do governo - tratamo-los separadamente. Armazenamos esses documentos por categoria (imprensa / governo), data, título e fonte no ATLAS.ti ${ }^{\circledR}$.

\section{Leitura dos textos e interpretação das observações empíricas}

Os textos foram lidos cronologicamente para fazer uma primeira descrição e identificar as representações sociais. Esta corresponde à primeira etapa da CDA. A maneira clássica de aplicação da CDA, utilizando o método de Fairclough, é dividida em três etapas: descrição, interpretação e explanação. Após a descrição minuciosa de cada segmento de texto, o segundo passo é a interpretação. A CDA sugere o uso de conceitos de sensibilização na fase de interpretação como uma estratégia para dar sentido e interpretar o papel constitutivo das práticas discursivas.
Tais conceitos podem surgir da análise ou podem ser emprestados de uma abordagem teórica. Em nossa análise, utilizamos os conceitos da TRS - os processos fundamentais, suas respectivas fases e possíveis falhas. Identificamos 441 fragmentos de textos e conectamos esses fragmentos por semelhanças. Entre as várias técnicas de CDA existentes, identificamos as quotations mais significativas e plenas de significado, e selecionamos essas quotations para identificar as representações sociais. Posteriormente, essas representações sociais são mobilizadas e articuladas na interpretação e explanação. Geramos 12 redes de análise. À medida que líamos e relíamos os textos, começamos a preencher os quadros das primeira e segunda etapas (descrição e interpretação), até que obtivemos estabilidade nos conceitos correspondentes à etapa de explanação.

\section{Explanação dos resultados}

A terceira coluna representa a explanação e é a última etapa a ser realizada em uma análise CDA. Isso significa conectar a interpretação com o contexto político, com a exploração de estruturas mais profundas refletidas pelos textos. Para prover essa conexão, mobilizamos as representações sociais obtidas na fase anterior, bem como a deficiência encontrada no processo de representação ao longo dos anos. 0 Quadro 2 contém um recorte dos quadros gerados e ilustra a leitura, interpretação e explanação com alguns fragmentos de textos. Pode parecer que os excertos dos textos foram retirados do contexto, mas, na análise, isso não foi feito. Apresentamo-los desarraigados do seu contexto para ilustrar como identificamos a ancoragem e/ou a objetificação. Destacamos que a explanação foi feita em um tempo diferente, depois da leitura/interpretação.

\section{TABELA 1. Resumo da coleta de dados}

\begin{tabular}{|c|c|c|c|c|c|c|}
\hline Ano & \multicolumn{4}{|c|}{ Instituições públicas ou fontes governamentais } & \multicolumn{2}{|r|}{ Imprensa } \\
\hline 2006 & 3 & \multirow{3}{*}{$\begin{array}{l}\text { Documentos } \\
\text { produzidos pelo } \\
\text { prefeito em seu } \\
\text { website }\end{array}$} & 3 & \multirow{3}{*}{$\begin{array}{c}\text { Documentos } \\
\text { publicados } \\
\text { no site da } \\
\text { prefeitura }\end{array}$} & 3 & \multirow{3}{*}{$\begin{array}{c}\text { Selecionados de jornais regionais e nacionais (O Estadão, } 0 \\
\text { Estado de Minas, Globo Minas, Voz das Gerais, TV Alterosa e } 0 \\
\text { Tempo), disponíveis na internet. }\end{array}$} \\
\hline 2008 & 5 & & 17 & & 30 & \\
\hline 2011 & 5 & & 8 & & 27 & \\
\hline Total & \multicolumn{4}{|c|}{41} & & 60 \\
\hline
\end{tabular}


Quadro 2. Exemplo do preenchimento do quadro de análise

\begin{tabular}{|c|c|c|c|c|c|}
\hline Ano & Texto & $\begin{array}{l}\text { Quotation } \\
\text { (Exemplos) }\end{array}$ & Descrição & Interpretação & Explanação \\
\hline 2006 & GOV-2006-005 & $\begin{array}{l}\text { "Pela primeira vez, } \\
\text { uma administração } \\
\text { municipal submeteu } \\
\text { à votação, pela } \\
\text { internet, obras a } \\
\text { serem executadas } \\
\text { em toda a cidade" }\end{array}$ & $\begin{array}{l}\text { O governo explica } \\
\text { o conceito de } \\
\text { OPD nomeando-o } \\
\text { como uma forma } \\
\text { de votação ou } \\
\text { possibilidade de } \\
\text { escolha. }\end{array}$ & $\begin{array}{l}\text { Processo: Ancoragem } \\
\text { Fase: Categorização } \\
\text { - Votação }(5)^{\star} \text { - Escolha }(6)^{\star} \\
\text { - Pioneirismo (1)* } \\
\text { Ferramenta }(1)^{\star}\end{array}$ & \multirow{2}{*}{$\begin{array}{l}\text { O governo não oferece } \\
\text { informações sobre as } \\
\text { possibilidades deliberativas, } \\
\text { apresentando o OP Digital como } \\
\text { uma ferramenta, como processo } \\
\text { de escolha, como forma de } \\
\text { votação ou disputa. Elementos } \\
\text { como e-participação e cidadania } \\
\text { não aparecem na ancoragem. } \\
\text { A representação da tecnologia } \\
\text { como ferramenta ilustra uma } \\
\text { visão instrumental, não uma } \\
\text { plataforma capaz de promover } \\
\text { melhor interação entre o governo- } \\
\text { cidadão. As representações } \\
\text { governamentais excluem o papel } \\
\text { político do cidadão, trivializa- } \\
\text { se o OP Digital, o conceito é } \\
\text { conhecido, mas reduzido. }\end{array}$} \\
\hline 2008 & GOV-2008-017 & $\begin{array}{l}\text { "O prefeito Fernando } \\
\text { Pimentel lançou, } \\
\text { nesta quarta-feira, } \\
\text { dia 12, o Orçamento } \\
\text { Participativo Digital } \\
\text { 2008." }\end{array}$ & $\begin{array}{l}\text { O governo explica } \\
\text { o conceito de OPD } \\
\text { nomeando-o como } \\
\text { uma forma de } \\
\text { votação, ou como } \\
\text { uma possibilidade } \\
\text { de escolha, ou, } \\
\text { ainda, como uma } \\
\text { disputa, ferramenta } \\
\text { de escolha. }\end{array}$ & $\begin{array}{l}\text { Processo: Ancoragem } \\
\text { Fase: Categorização } \\
\text { - Votação }(31)^{\star} \\
\text { - Escolha }(13)^{\star} \\
\text { - Disputa }(4)^{\star} \\
\text { - Ferramenta (1)* }\end{array}$ & \\
\hline 2011 & IMP-2011-013 & $\begin{array}{l}\text { "Está aberta a } \\
\text { votação de mais } \\
\text { um orçamento } \\
\text { participativo de Belo } \\
\text { Horizonte" }\end{array}$ & $\begin{array}{l}\text { A imprensa explica } \\
\text { o conceito de } \\
\text { OPD nomeando-o } \\
\text { como uma forma } \\
\text { de votação ou } \\
\text { possibilidade } \\
\text { de escolha. } \\
\text { Caracteriza-o como } \\
\text { um mecanismo } \\
\text { de seleção ou de } \\
\text { eleição. }\end{array}$ & $\begin{array}{l}\text { Processo: Ancoragem } \\
\text { Fase: Categorização } \\
\text { - Votação }(23)^{\star} \\
\text { - Escolha }(5)^{\star} \\
\text { - Disputa }(6)^{\star} \\
\text { - Eleição }(1)^{\star}\end{array}$ & $\begin{array}{l}\text { Tal como no governo, na } \\
\text { ancoragem da imprensa há } \\
\text { trivialização do OP Digital, } \\
\text { esvaziando-o de algumas } \\
\text { características que são novas, } \\
\text { a possibilidade de deliberação, } \\
\text { reduzindo-o àquilo que já } \\
\text { é conhecido - uma votação } \\
\text { eletrônica. }\end{array}$ \\
\hline 2006 & GOV-2006-007 & $\begin{array}{l}\text { "simplesmente } \\
\text { "OP Digital", } \\
\text { esse verdadeiro } \\
\text { retorno tecnológico } \\
\text { ao Ágora dos } \\
\text { atenienses, o } \\
\text { exemplo genuíno da } \\
\text { democracia direta" }\end{array}$ & $\begin{array}{l}\text { O governo seleciona } \\
\text { elementos abstratos } \\
\text { para caracterizar o } \\
\text { OP Digital. }\end{array}$ & $\begin{array}{l}\text { Processo: Objetificação } \\
\text { Fase: Seleção (1)* }\end{array}$ & $\begin{array}{l}\text { Abstratização, distancia-se das } \\
\text { características do OP Digital. }\end{array}$ \\
\hline 2008 & IMP-2008-027 & $\begin{array}{l}\text { "Na última edição } \\
\text { do Orçamento } \\
\text { Participativo Digital } \\
\text { (OP Digital) - } \\
\text { versão eletrônica } \\
\text { do programa - a } \\
\text { prefeitura decidiu } \\
\text { fazer a seleção com } \\
\text { base num tema: } \\
\text { trânsito" }\end{array}$ & $\begin{array}{l}\text { A imprensa } \\
\text { seleciona elementos } \\
\text { para representar } \\
\text { o OPD, o uso } \\
\text { da internet e do } \\
\text { computador, um } \\
\text { instrumento de } \\
\text { participação } \\
\text { popular. }\end{array}$ & $\begin{array}{l}\text { Processo: Objetificação } \\
\text { Fase: Seleção } \\
\text { - Instrumento digital (4)* } \\
\text { - Info.acesso aos meios } \\
\text { eletrônicos (6)* } \\
\text { - Participação popular (5)* } \\
\text { - Inovação (1)* }\end{array}$ & $\begin{array}{l}\text { Reificação do OP Digital como } \\
\text { instrumento eletrônico é } \\
\text { enfática nos textos da imprensa. } \\
\text { A construção do conceito é } \\
\text { de instrumento digital para } \\
\text { participação em uma votação. } \\
\text { Há menção a instrumento de } \\
\text { participação em menor número, } \\
\text { excluindo-se o papel ativo do } \\
\text { cidadão no debate político. }\end{array}$ \\
\hline
\end{tabular}


Quadro 2. Exemplo do preenchimento do quadro de análise

(conclusão)

\begin{tabular}{|c|c|c|c|c|c|}
\hline Ano & Texto & $\begin{array}{l}\text { Quotation } \\
\text { (Exemplos) }\end{array}$ & Descrição & Interpretação & Explanação \\
\hline 2008 & GOV-2008-006 & $\begin{array}{l}\text { “Para quem não } \\
\text { tem acesso à } \\
\text { internet, a Prefeitura } \\
\text { vai disponibilizar } \\
271 \text { locais de } \\
\text { votação. Os } \\
\text { endereços de todos } \\
\text { esses locais estão } \\
\text { disponíveis nos } \\
\text { sites da Prefeitura e } \\
\text { do OP Digital.” }\end{array}$ & $\begin{array}{l}\text { O Governo seleciona } \\
\text { elementos para } \\
\text { representar o OPD, } \\
\text { o uso da internet } \\
\text { e computador, } \\
\text { um instrumento } \\
\text { de participação } \\
\text { popular. }\end{array}$ & $\begin{array}{l}\text { Processo: Objetificação } \\
\text { Fase: Seleção } \\
\text { - Instrumento digital (6)* } \\
\text { - Info. acesso aos meios } \\
\text { eletrônicos (9)* } \\
\text { - Participação popular (4)* } \\
\text { - Inovação (3)* } \\
\text { - Governança } \\
\text { participativa (2)* } \\
\text { - Gestão compartilhada (1)* }\end{array}$ & $\begin{array}{l}\text { A ênfase da seleção e } \\
\text { descentralização de elementos } \\
\text { do OP Digital é no sentido de } \\
\text { evidenciar o meio eletrônico. } \\
\text { Refere-se a tecnologia como } \\
\text { instrumento, ferramenta. } \\
\text { Reificação do OP Digital até na } \\
\text { denominação escolhida - o que } \\
\text { fica em evidência é o digital. }\end{array}$ \\
\hline
\end{tabular}

Nota: * Número de quotations da análise

\section{APRESENTAÇÃO E DISCUSSÃO DOS RESULTADOS}

Nesta seção, descrevemos o OP Digital de BH antes de apresentar e discutir os resultados da pesquisa.

\section{O objeto de estudo: 0 OP Digital de BH}

Uma relativa variedade de processos participativos está sendo implementada na administração pública brasileira, tais como audiências e consultas públicas, cooperação de entidades representativas da sociedade civil, participação dos usuários na prestação de serviços públicos, OP, reuniões públicas, pesquisas, uso de focus groups e conselhos de cidadãos. Um OP busca, em termos gerais, a participação pública no processo de elaboração do orçamento da cidade e tem sido descrito como deliberativo, um processo decisório coletivo de governo e cidadãos.

Em 1993, o governo local de BH, capital de Minas Gerais, implementou sua própria versão de OP. A cidade tem mais de 2,3 milhões de habitantes, mais de 1,7 milhão de eleitores e é dividida em nove administrações regionais. No processo tradi- cional do OP, os fóruns distritais (41) pré-selecionam obras públicas (25) para cada região. Nos fóruns, cada região também elege os seus delegados sub-regionais. São organizadas visitas para que os delegados regionais conheçam em conjunto os locais das obras pré-selecionadas. Os delegados regionais escoIhem um máximo de 14 obras por região e podem supervisionar a sua execução. De 1993 até 2011, foram concluídas mais de mil obras públicas do OP (Prefeitura BH, 2008).

Em 2006, o governo municipal criou o OP Digital para ser implementado em dois anos - 2007/2008, envolvendo consultas aos cidadãos baseadas em uma plataforma internet. Os cidadãos podiam votar nas obras que julgavam mais necessárias, usando computadores instalados em diversas regiões da cidade. Eleitores registrados no município, independentemente do seu local de residência, poderiam escolher, exclusivamente on-line, nove obras públicas de 36 disponíveis. Além do orçamento de aproximadamente 40 milhões de dólares alocados ao OP tradicional, o OP Digital contou com 10 milhões de dólares adicionais. Uma campanha de comunicação foi desenvolvida pela prefeitura (TV, rádio, panfletos, website), que instalou 178 pontos de votação pela internet, com mais de 500 computadores e pessoal treinado para suporte aos votantes, ao longo de 40 dias. Para ob- 
ter mobilidade, alguns dos pontos de votação foram colocados em ônibus equipados com acesso à internet. A prefeitura contou com vários parceiros voluntários, tais como associações comerciais, igrejas e associações comunitárias, que instalaram pontos públicos de internet adicionais para facilitar o acesso daqueles que queriam participar. Um website (http://opdigital.pbh.gov.br) continha as informações sobre o OP Digital, fóruns de cidadãos, notícias, fotos dos locais selecionados, perguntas frequentes (FAQs) e a lista dos pontos públicos de acesso à internet. Cerca de 173 mil votantes (aproximadamente 500 mil votos computados) participaram dessa edição.

Em 2008, o OP Digital foi parcialmente modificado. Os recursos para os investimentos foram ampliados em $147 \%$ e foram selecionadas cinco obras viárias para a escolha de uma que beneficiasse toda a população (cada eleitor teve direito a um único voto). Além da disponibilidade da internet, foi dada ao cidadão a possibilidade de fazer sua escolha por meio de uma ligação gratuita. A participação foi, no entanto, menos expressiva do que na primeira edição. Em 2008, aproximadamente 124 mil votos foram computados no OP Digital.

Em 2011, a prefeitura de BH lançou a terceira edição do OP Digital. Novas regras de segurança foram adotadas. Para votar, o cidadão precisou instalar o aplicativo da prefeitura para executar o programa de votação e cadastrar um e-mail para receber a confirmação da participação. Foram selecionados 36 empreendimentos, sendo quatro por regional, de acordo com a demanda e disponibilidade orçamentária. Cada eleitor poderia escolher nove obras públicas, uma por regional. A participação em 2011 foi ainda menor, com cerca de 25 mil votantes (aproximadamente 92 mil votos), $14 \%$ da primeira edição.

\section{Análise dos dados}

Apesar de todo o esforço de comunicação que se estendeu pelo governo municipal de $\mathrm{BH}$ para familiarizar a população com 0 OP Digital, esse objetivo não foi alcançado. Nossa análise dos documentos de 2006, 2008 e 2011 mostra que o funcionamento do OP Digital - o que é, quando participar, como participar - foi exaustivamente apresentado, tornando-se, muitas vezes, repetitivo. Nós encontramos, também, alguns textos idênticos apresentados em anos diferentes. Na nossa análise, apoiada na TRS, examinamos os processos de ancoragem-objetificação no OP Digital.

\section{Ancoragem}

Ancoragem consiste em compreender um objeto em função do outro, o desconhecido está ancorado no conhecido. Ele adquire suas características e leva seus problemas e qualidades de modo análogo. As representações que lideram o processo de ancoragem para dar sentido ao OP Digital são: votação, escolha, eleição (os três ligados em última análise à ideia de votação) e ferramenta tecnológica. Não identificamos diferenças significativas entre as categorizações promovidas pelo governo e pela imprensa. Essa categorização influenciará o processo que se segue na objetificação. 0 Quadro 3 resume esse processo.

\section{Quadro 3. Resultados do processo de ancoragem}

\begin{tabular}{l|l|l|l}
\hline Ano & $\begin{array}{l}\text { Ancoragem (do } \\
\text { Governo) }\end{array}$ & $\begin{array}{l}\text { Ancoragem (da } \\
\text { imprensa) }\end{array}$ & Categorização \\
\hline \multirow{2}{*}{2006} & $\begin{array}{l}\text { Meios de } \\
\text { votação; } \\
\text { processo de } \\
\text { escolha. }\end{array}$ & $\begin{array}{l}\text { Meios de } \\
\text { votação; } \\
\text { processo } \\
\text { de escolha; } \\
\text { ferramenta } \\
\text { tecnológica. }\end{array}$ & $\begin{array}{l}\text { OP Digital como } \\
\text { voto } \\
\text { OP Digital como } \\
\text { ferramenta }\end{array}$ \\
\hline \multirow{2}{*}{2008} & $\begin{array}{l}\text { Meios de } \\
\text { votação; } \\
\text { processo } \\
\text { de escolha; } \\
\text { ferramenta } \\
\text { tecnológica. }\end{array}$ & $\begin{array}{l}\text { Meios de } \\
\text { votação; } \\
\text { processo } \\
\text { de escolha; } \\
\text { processo de } \\
\text { eleição. }\end{array}$ & $\begin{array}{l}\text { OP Digital como } \\
\text { ferramenta }\end{array}$ \\
\hline \multirow{2}{*}{2011} & $\begin{array}{l}\text { Meios de } \\
\text { votação; } \\
\text { processo } \\
\text { de escolha; } \\
\text { ferramenta } \\
\text { tecnológica. }\end{array}$ & $\begin{array}{l}\text { Meios de } \\
\text { votação; } \\
\text { processo } \\
\text { de escolha; } \\
\text { processo de } \\
\text { eleição. }\end{array}$ & $\begin{array}{l}\text { OP Digital como } \\
\text { voto } \\
\text { OP Digital como } \\
\text { ferramenta }\end{array}$ \\
\hline
\end{tabular}

\section{Objetificação}

A objetificação produz um vocabulário e um reservatório de imagens (o conceito como objeto) que podem servir como referência para os membros do grupo, para selecionar e escolher características desse objeto que o distinguem dos outros. As três etapas da objetificação na TRS são a seleção, a esquematização e a naturalização. Com base nos textos que analisamos, foi possível identificar que, de duas principais categorias produzidas na fase anterior (votação e ferramenta), na objetificação, a segunda (ferramenta) torna-se mais aparente. O OP Digital perde seu caráter processual e passa a ser cristalizado como uma ferramenta. Os termos ponderam sua utilização sobretudo ao uso da internet e do computador, ao eletrônico, ao digital, ao uso da tecnologia para a participação popular. O foco é na tecnologia, na ferramenta. Encontramos no texto governamental, no entanto, elementos relacionados à democracia, governança 
participativa e decisão popular, ainda que em menor número e repetidos de maneira idêntica ao longo dos anos. 0 Quadro 4 apresenta esse processo.

\section{Quadro 4. Resultados do processo de objetificação}

\begin{tabular}{|c|c|c|}
\hline Ano & Objetificação (do Governo) & $\begin{array}{l}\text { Objetificação } \\
\text { (da imprensa) }\end{array}$ \\
\hline $\begin{array}{l}2006 \\
2008 \\
2011\end{array}$ & $\begin{array}{l}\text { OP Digital é primeiramente } \\
\text { objetificado como tecnologia } \\
\text { (internet e computadores, } \\
\text { tecnologia eletrônica ou digital); } \\
\text { marginalmente, a democracia como } \\
\text { o foco secundário (democracia, } \\
\text { governança participativa, decisão } \\
\text { popular). }\end{array}$ & $\begin{array}{l}\text { OP Digital é } \\
\text { objetificado } \\
\text { como tecnologia } \\
\text { (internet e } \\
\text { computadores, } \\
\text { tecnologia } \\
\text { eletrônica ou } \\
\text { digital). }\end{array}$ \\
\hline
\end{tabular}

Além das representações sociais do OP Digital que buscamos nos textos do governo e imprensa, encontramos, na análise dos dados, elementos que valem ser destacados. No discurso do governo, nos três anos de edição, há inúmeros fragmentos referenciando as premiações concedidas ao OP Digital, nacional e internacionalmente, por uma iniciativa inovadora na democracia participativa, o que pouco aparece no discurso da imprensa. Por outro lado, na imprensa, há elementos que não foram discutidos nos textos do governo. Em 2008 e 2011, há discussões na imprensa a respeito de fraudes e de falta de perspectiva para a conclusão das obras aprovadas.

IMP_2011_002: “Em 2008, pela primeira vez, ele votou numa obra, a de restauro da Praça São Vicente, no Bairro Alípio de Melo, Região Noroeste de Belo Horizonte, mas até hoje a benfeitoria não saiu do papel. 'Como é que podem colocar uma obra para ser votada se ela depois não é realizada?', reclama. [...] 'Estou muito decepcionado e não quero mais saber de votar', afirmou".

O governo manifesta-se, enfaticamente, sobre o início das obras do OP Digital. Em 2011, tanto na imprensa quanto no governo, emerge o combate às fraudes.

\section{Discussão dos resultados}

Na primeira leitura dos textos de 2006, verificamos a ausência de vozes discordantes e de oposição ao prefeito. Pode ser silêncio nessa matéria específica ou reflexo do acordo político em vigor à época em Minas Gerais. A oposição dos dois maiores partidos políticos, acirrada no cenário nacional, era quase inexistente no Estado. Ainda na leitura preliminar, antes da aposição da lente teórica aos textos, percebemos a fala governamental literalmente reproduzida na imprensa. Há que se refletir sobre a importância da esfera pública na sociedade democrática, no papel da mídia e de outros atores ao se formatar o discurso público. Nesse caso, a voz do governo foi a da imprensa, o que pode fazer com que o ator mais poderoso imprima marcadamente a sua representação do novo objeto à comunidade. Em sua maioria, a comunicação é repetitiva, concentrando-se em informar o leitor sobre os aspectos operacionais do OP Digital, como datas importantes, locais de votação e documentos necessários para a participação. Há poucas menções ao potencial deliberativo do OP. Uma delas, em 2011, é cópia exata de um texto de 2008.

Para Moscovici (2001), é em função das representações dos objetos sociais que os indivíduos e as coletividades realizam suas ações. Uma representação social é produto da iteração e interação de dois processos fundamentais, a ancoragem e a objetificação.

$\mathrm{Na}$ ancoragem, tanto a imprensa quanto o governo trivializam o OP Digital. Há poucos traços do novo objeto que o distinguem no ambiente, ancorando-o nas características dos objetos conhecidos, como votação ou escolha. Não são quase debatidas, por exemplo, as possibilidades de ampliação da participação na discussão pública, melhor governança com meIhores decisões, ou a corresponsabilidade do cidadão na tomada de decisão pública. Com essa trivialização, coloca-se muita ênfase nas práticas conhecidas. Para tornar o conceito mais facilmente adotado pelo público, perde-se a oportunidade de apontar questões de valor e impacto do OP Digital, ou do uso das tecnologias no estabelecimento do orçamento público, em comparação com os processos de votação já estabelecidos. Os textos moldam discursos, que produzem um sistema de relações de poder, que estruturam um contexto no qual a ação acontece, toma lugar (Hardy \& Phillips, 2004). Ao escrever sobre o OP Digital como uma votação, eleição ou escolha, imprensa e governo excluem o papel político ativo do cidadão na deliberação, no debate possibilitado pelo uso das TIC. Também definem o seu papel, pois, num processo de votação, são minimizadas as exigências de provimento de boa e ampla informação, e de ofertar uma forma de comunicação entre os cidadãos para o debate público. Além da ancoragem por meio da representação da votação, a apresentação do OP Digital como ferramenta tecnológica reforça a trivialização das várias possibilidades e representações alternativas da participação digital. A tecnologia de informação é descrita de modo instrumental, e não efetivamente, como uma plataforma transformadora para promoção de interação entre o governo e o cidadão. Apresentado como votação ou eleição, o OP Digital reproduz o status quo.

Na objetificação, identificamos reificação, mais frequentemente nos textos da imprensa. A prática social é esvaziada 
do seu aspecto emblemático de participação na tomada de decisão pública e rendida ao aspecto de um instrumento digital para uma votação. 0 nome que o governo imprime ao novo objeto, ao mesmo tempo que o ancora no processo do OP, denota a evidenciação da característica digital que o diferencia, grafando-o como OP Digital. Isso tem implicações em como se dá sentido à participação, na forma como se articula o poder. O OP Digital de BH, seguindo a classificação proposta por Ainsworth et al. (2005), pode ser tipificado como e-democracia consultiva, isto é, foca-se a comunicação entre Estado e cidadãos. De fato, a possibilidade de interação existia, no fórum Debates, mas ela pouco emerge dos textos, pouco aparece como uma das características do OP Digital. A ênfase da apresentação nos prêmios recebidos e na tecnologia por ela mesma retira do OP Digital as características de participação, de corresponsabilidade, de possibilidade de deliberação, tanto entre governo e cidadãos como com todos os participantes do processo democrático - gestores públicos, cargos políticos e cidadãos. O OP Digital está longe de ser um processo deliberativo, uma tomada de decisão ativa, na qual os cidadãos interessados, organizações, agências e grupos interagem para decidir. E essa é a intenção declarada, a proposta governamental é incluir no debate do orçamento da cidade grupos que dele não participavam. Compartilha-se informação governamental com os cidadãos, pelo site, por e-mails, respondendo a perguntas, e recebe-se deles a escolha. A preocupação concentra-se mais, no entanto, na distribuição de informação do que na promoção da interação entre os atores sociais com o uso das TIC. Nesse caso, os meios eletrônicos não promovem a construção coletiva: há uma consulta à sociedade pelo governo. Esse ator, mais poderoso, pode até estar aumentando seu poder, legitimando os resultados do processo de orçamento da cidade pela consulta à população. Veja-se que as obras do OP Digital não são o total do OP, são cerca de $20 \%$, e o OP também é apenas uma parte do orçamento da cidade.

Menções da imprensa à não realização das obras previstas e à ocorrência de fraudes são manifestações contrárias (em pequeno número), mas podem também explicar a resistência à participação para uma legitimação das práticas do poder estabelecido. Se tudo continua igual, talvez não haja interesse em participar. Poderia haver maior interesse se os cidadãos entendessem que, com o uso das tecnologias, há possibilidade de se vencer a distância entre aquilo que percebem como importante e o que é realizado pelos governos (Boon et al, 2011).

Merece ser feita uma observação à ausência da agenda de participação (Puri \& Sahay, 2007), ou seja, o cidadão não participa da decisão que reserva o orçamento público para o OP e, em 2008, não foi chamado a definir se haveria uma escolha entre 10 obras viárias (por que 10, por que viárias?). Não houve fortalecimento das habilidades que permitem ao cidadão uma participação mais informada, por exemplo, sobre orçamento público, ou melhoria de habilidades no uso da internet como fonte de informação. 0 fracasso de uma obra escolhida como prioritária pelo OP Digital, devido a dificuldades de interação com o governo federal e destinação de recursos federais, mostra que há barreiras em integrar essa experiência participatória local em tomadas de decisão que envolvam redes mais amplas.

\section{CONCLUSÃO}

Neste artigo, quisemos compreender as representações sociais da tomada de decisão pública mediada por TIC. Investigamos o caso do OP Digital de BH e as possíveis razões da queda na participação ao longo dos anos.

Em primeiro lugar, descobrimos que o governo e a imprensa ancoram a introdução de um novo processo digital, principalmente em votação, trivializando-o, e depois reificando-o como um dispositivo eletrônico e um vencedor de prêmios. 0 processo de ancoragem equiparando e-participação com o direito a voto pode fazer com que aqueles que queriam usar as TIC para melhorar os processos democráticos percam o interesse. Opinião, informação, formação aberta, direitos de voz, os processos participativos são tão importantes quanto a votação em si. Igualando a e-participação à e-votação, entretanto, trivializa-se a possibilidade da TIC na melhoria dos processos democráticos. Apresentar o OP Digital como uma eleição ou uma votação carrega o novo objeto de uma carga simbólica particular à democracia no País: descrédito nas instituições e no poder de mudança dos processos eleitorais. O OP Digital como votação, eleição ou escolha, nos textos da imprensa e governo, define um discurso em que o cidadão não tem um papel ativo e para o qual são minimizadas as exigências de provimento de boa e ampla informação. Cabe a chamada às possibilidades de participação mais amplas, como na discussão da agenda de participação e/ou na agenda das políticas públicas (Puri \& Sahay, 2007).

Em segundo lugar, o processo de reificação transmitindo o OP Digital como uma tecnologia, uma mera ferramenta, ajuda a explicar a queda no número de indivíduos, especialmente quando rumores sobre fraudes e atrasos começaram a aparecer na imprensa. Visto apenas como uma ferramenta, o OP Digital perde seu potencial transformador como uma plataforma de empowerment do cidadão na sua relação com o governo, perde relevância, distanciando-se do sentido deliberativo da participação pública. Formas emancipatórias da utilização das TIC exigem o envolvimento dos cidadãos, que participam de um 
processo ativo, e reconhecimento deles como atores no debate político. Esta pode ser uma contribuição aos gestores públicos que lidam com a implementação de mecanismos de participação eletrônica - considerar que a TIC, mais que uma ferramenta, é uma possibilidade de exercício ativo da cidadania.

Em terceiro lugar, o discurso governamental não aponta novas possibilidades de interação. A nossa revisão de literatura, apesar de ter apontado visões antagônicas sobre o uso de internet na prática democrática, leva-nos a crer que o potencial de interação da internet pode ser uma força para a ampliação da prática democrática. Alguns estudos comentaram o fracasso de tirar vantagem dessa capacidade de interação como uma estratégia política (Ainsworth et al, 2005; Bimber, 1998). Nosso estudo vai além desse argumento, os resultados nos indicam que a estratégia política pode ser a de não explorar o potencial de interação e construção coletiva da internet, ancorando a nova prática em uma votação, um pleito eletrônico, trivializando-a. Chama a atenção, na imprensa, o espaço reduzido dedicado à discussão do OP Digital, seus limites e potencialidades. Os textos são marcadamente informativos. Ressaltamos que não encontramos textos de outros atores com críticas ou reforço da posição do governo sobre o OP Digital por exemplo, de partidos ou adversários políticos do prefeito. O discurso governamental não aponta a mudança, a imprensa reproduz esse discurso, e nele não se deu espaço a vozes dissonantes.

Finalmente, acreditamos que o nosso trabalho mostra que a pesquisa no uso e implicações sociais de tecnologia pode ser enriquecida pelo emprego de um corpo de teoria multidisciplinar já estabelecido em outras áreas, como a TRS. 0 trabalho iniciado neste artigo poderá ser ampliado. Para WW, há uma dimensão de resistência no discurso, que se opõe ao poder estabelecido. As práticas discursivas carregam essa dimensão. Nosso trabalho evidenciou o caráter de aparelhamento, de reprodução do status quo, investigando os discursos de imprensa e governo. As representações sociais formam-se, porém, na interação comunicativa de um determinado grupo social; será interessante conhecer as representações sociais de grupos particulares, por exemplo, de cidadãos que se engajaram no movimento do OP Digital, e compará-las com a que emerge deste nosso trabalho.

\section{Nota de agradecimento}

Agradecemos ao Conselho Nacional de Desenvolvimento Científico e Tecnológico (CNPQ) pelo apoio financeiro à pesquisa “As TICs para incremento da participação na tomada de decisão pública” que deu origem a este artigo.

\section{REFERÊNCIAS}

Abric, J. C. (1994). Méthodologie de recueil des représentations sociales. In J. C. Abric. Pratiques socials et représentations (pp. 59-82). Paris: Presses Universitaires de France.

Ainsworth, S, Hardy, C, \& Harley, B. (2005). Online consultation: e-democracy and e-resistance in the case of the development gateway. Management Comunication Quartely, 19(1), 120-145.

Audebrand, L, \& lacobus, A. (2008). Avoiding potential traps in fair trade marketing: a social representation perspective. Journal of Strategic Marketing, 16(1), 3-19.

Avgerou, C. (2008). Information systems in developing countries: a critical research review. Journal of Information Technology, 23(3), 133-146.

Bimber, B. (1998). The internet and political transformation: populism, community and accelerated pluralism. Polity, 31(1), 133-160.

Boon, A, Jansen, M, \& Veenestra, A. F. (2011). Measure to improve: a study of eParticipation in frontrunner Dutch municipalities. International Federation for Information Processing, 6847, 157-168.

Brooke, C. (2002). What does it mean to be 'critical' in IS research? Journal of Information Technology, 17(2), 49-57.

Contarello, A, \& Sarrica, M. (2007). ICTs, social thinking and subjective well-being - the internet and its representations in everyday life. Computers in Human Behavior, 23(2), 1016-1032.

Cukier, W, Ngwenyama, O, Bauer, R, \& Midletton, C. (2008). A critical analysis of media discourse on information technology: preliminary results of a proposed method for critical discourse analysis. Info Systems Journal, 19(2), 175-196.

Dertouzos, M. (1997). What will be: how the new information marketplace will change our lives. San Francisco: Harper.

Doolin, B. (1998). Information technology as disciplinary technology: being critical in interpretative research on information systems. Journal of Information Technology, 13(4), 301-311.

Fairclough, N. (1995). Critical discourse analyses: the critical study of language. London: Longman.

Fairclough, N. (1996). A reply to Henry Winddowson's discourse analyses: a critical view. Language and Literature, 5(1), 49-56.

Gal, U, \& Berente, N. (2008). A social representations perspective on information systems implementation: rethinking the concept of "frames". Information Technology \& People, 21(2), 133-154.

Hardy, C, \& Phillips, N. (2004). Discourse and power. In D. Grant, C. Hardy, C. Oswick, \& L. Putnam (Eds.). Handbook of organizational discourse (pp. 299-316). London: Sage.

Kaganer, E, \& Vaast, E. (2010). Responding to the (almost) unknown: social representations and corporate policies of social media. Proceedings of the International Conference on Information Systems, Saint Louis, MO, USA. Retrieved 3 September, 2012 from http://aisel.aisnet.org/ icis2010 submissions $/ 163$

Kling, R. (Ed.). (1996). Hopes and horrors: technological utopianism and anti-utopianism in narratives of computerization. In R. Kling. Computerization and controversy: value conflicts and social choices. San Diego, CA: Academic Press.

Macintosh, A. (2004). Characterizing e-participation in policy-making. Proceedings of the 37th Annual Hawaii International Conference on System Sciences. Honolulu, HI, USA. 
Macintosh, A. (2007). Challenges and barriers of eParticipation in Europe? Mendeley. Retrieved 27 May, 2012, from http://www.sweden.gov. se/content/1/c6/08/49/42/9d411e53.pdf

Moscovici, S. (1961). La psychanalyse, son image et son public. Paris: Presses Universitaires de France.

Moscovici, S. (2001). The phenomenon of social representations. In G. Duveen (Ed.). Social representations: explorations in social psychology. New York: New York University Press.

Negroponte, N. (1995). Being digital. New York: Knopf.

Ngwenyama, O. K, \& Lee, A. S. (1997). Communication richness in electronic mail: critical social theory and the contextually of meaning. MIS Quarterly, 21(2), 145-167.

Pawlowski, S. D, Kaganer, E. A, \& Cater, J. J, III (2007). Focusing the research agenda on burnout in IT: social representations of burnout in the profession. European Journal of Information Systems, 16(5), 612-627.

Pinho, J. A. G. (2011). Sociedade da informação, capitalismo e sociedade civil: reflexões sobre política, internet e democracia na realidade brasileira. RAE-Revista de Administração de Empresas, 51(1), 98-106.

Pozzebon, M. (2003). The implementation of configurablet Technologies: negotiations between global principles and local contexts. Doctoral dissertation, McGill University, Montreal, Quebec, Canadá.

Prefeitura BH (2008). Revista Comemorativa do Orçamento Participativo de Belo Horizonte - 15 anos.

Puri, S. K, \& Sahay, S. (2007). Role of ICTs in participatory development: an Indian experience. Information Technology for Development, 13(2), 133-160.
Rose, J, Grönlund, A, \& Andersen, K. V. (2007). What is eParticipation?. In A. Avdic, K. Hedström, J. Rose, Å. Grönlund (Eds.). Understanding eParticipation: contemporary PhD eParticipation studies in Europe. Sweden: Örebro University Library.

Sæbø, Ø, Rose, J, \& Flak, K. S. (2008). The shape of eParticipation: characterizing an emerging research area. Government Information Quarterly, 25(3), 400-428.

Savazoni, R, \& Cohn, S. (Orgs.). (2009). Cultura digital.br. Rio de Janeiro: Beco do Azougue.

Sorj, B. (2003).Brasil@povo.com: a luta contra a desigualdade na sociedade de informação. Rio de Janeiro: Zahar.

Susha, I, \& Grönlund, A. (2012). eParticipation research: systematizing the field. Government Information Quarterly, 29(3), 373-382.

Thompson, M. P. A. (2004). ICT, power, and developmental discourse: a critical analysis. The Electronic Journal of Information Systems in Developing Countries, 20(4), 1-26.

Vaast, E. (2007). Danger is in the eye of the beholders: social representations of information systems security in healthcare. Journal of Strategic Information Systems, 16(2), 130-152.

Vaast, E, \& Walsham, G. (2005). Representations and actions: the transformation of work practices with IT use. Information and Organization, 15(1), 65-89.

Vergara, S. C, \& Ferreira, V. C. P. (2005). A representação social de ONGs segundo formadores de opinião do município do Rio de Janeiro. Revista de Administração Pública, 39(5), 1137-1159.

Winner, L. (1986). Myth information: romantic politics in the information age. In C. Mitcham \& A. Huning (Eds.). Philosophy and technology II: information technology and computers in theory and practice. Holanda: D. Reidel Publishing Company. 